\title{
Kohesi dalam Novel Surat Kecil untuk Tuhan
}

\author{
Sri Puji Astuti \\ Fakultas Ilmu Budaya, Universitas Diponegoro \\ sripujiastuti0116@gmail.com
}

\begin{abstract}
This study uses the Surat Kecil untuk Tuhan novel (NSK) as a data source. The language used in this novel is very interesting. Therefore, cohesion is used in this novel as a marker. This study aims to decipher lexical cohesion markers and grammatical cohesion markers used in the Surat Kecil untuk Tuhan. In collecting data, the researchers first listened to the use of the language used in the novel then continued with the note taking technique. The results of the analysis found that to form a coherent discourse the author of the Surat Kecil untuk Tuhan uses lexical cohesion markers and grammatical cohesion markers.
\end{abstract}

Keywords: Cohesion markers; lexical; grammatical; and novel.

\section{Intisari}

Penelitian ini mengunakan novel Surat Kecil untuk Tuhan (NSK) sebagai sumber data. Novel ini menggunakan bahasa yang sangat menarik. Oleh sebab itu, dalam novel ini diduga digunakan penanda kohesi. Penelitian ini bertujuan menguraikan penanda kohesi leksikal dan gramatikal apa sajakah yang digunakan oleh penulis dalam NSK. Langkah penelitian, mula-mula peneliti menyimak pemakaian bahasa yang digunakan dalam novel tersebut kemudian dilanjutkan dengan teknik catat. Teknik catat digunakan untuk mencatat penggalan wacana yang mengandung kohesi gamatikal dan kohesi leksikal yang terdapat dalam NSK.. Hasil analisis menemukan bahwa untuk membentuk wacana yang padu penulis novel Surat Kecil untuk Tuhan menggunakan penanda kohesi leksikal dan kohesi gramatikal.

Kata kunci: Penanda; kohesi; leksikal; gramatikal; dan novel.

\section{Pendahuluan}

Bahasa yang digunakan dalam novel tentunya harus dapat menarik minat pembaca. Untuk menarik minat pembaca, penulis novel ini diduga menggunakan piranti kohesi. Penggunaan piranti kohesi biasanya akan mempermudah pembaca memahami pesan yang disampaikan penulis. Hal ini terjadi karena jika ada kisah yang menarik tetapi ditulis dengan bahasa yang tidak menarik, pembaca akan merasa kesulitan memahami pesan novel bahkan bosan membaca novel tersebut. Jika pembaca sudah bosan atau mengalami kesulitan, akhirnya pembaca tidak membaca novel tersebut sampai selesai. Oleh karena itu, Penulis Surat kecil 
untuk Tuhan diduga menggunakan bahasa yang mudah dipahami pembacanya Hal ini terbukti dengan adanya pencetakan novel tersebut secara berulang-ulang. Makalah ini mengungkap jenis kohesi leksikal dan gramatikal apa sajakah yang terdapat dalam NSK.

Wacana yang padu dapat diciptakan dengan menggunakan penanda kohesi. (Djajasudarma, 1994:46). Kohesi leksikal adalah hubungan antarunsur dalam wacana secara semantis (Sumarlam, 2003:34). Unsur kohesi leksikal dalam wacana terdiri atas repetisi, sinonimi, antonimi, kolokasi, hiponimi, dan ekuivalensi.

Pengulangan juga dapat mempertahankan topik atau ide yang sedang dibicarakan sehingga topik kalimat masih saling berkaitan (Rani, 2004:130).Selanjutnya, (Sumarlam, 2003:34) mengklasifikasikan repetisi berdasarkan tempat satuan lingual yang diulang. Sinonim adalah dua kata atau lebih yang mempunyai arti mirip. Dikatakan hampir sama karena kedua kata atau lebih tersebut tidak selamanya bisa saling menggantikan. Verhaar (dalam Pateda,1996: 224-225) mengklasifikasikan sinonim menurut taraf keberadaan bentuk dapat dibedakan menjadi (1) sinonim antarkalimat, (2) sinonim antarfrasa, (3) sinonim antarkata, dan (4) sinonim antarmofem. Antonim disebut juga dengan istilah oposisi. Dilihat dari sifat hubungannya oposisi dapat dibedakan menjadi lima jenis yaitu oposisi mutlak, oposisi kutub, oposisi hubungan, oposisi herarkial, dan oposisi majemuk (Sumarlam, 2003: 39-42). Kolokasi adalah kata-kata yang terdapat dalam lingkungan yang sama (Sumarlam,2003:43). Kridalaksana (dalam Wijana dan Muhammad Rohmadi, 2011:53) menjelaskan dalam hiponim terdapat hubungan semantik generic spesifik. Dalam hiponim terdapat istilah superordinat dan subordinat. Ekuivalensi dalam wacana terjadi jika ada kata turunan yang terbentuk dari kata dasar yang sama.

Kohesi gramatikal meliputi: pengacuan, penyulihan, pelesapan, dan perangkaian. Pengacuan bisa berwujud kata atau frasa yang mengacu pada unsur bahasa yang lain (Sumarlam, 2003:23). Substitusi dalam wacana terjadi jika terdapat penggantian kata, frasa atau klausa dengan unsur bahasa lain dalam wacana (Sumarlam, 2003:28). Elipsis adalah penghilangan unsur bahasa yang telah disebutkan sebelumnya. Elipsis dalam wacana dapat berupa kata, frasa, klausa, atau kalimat (Sumarlam, 2003:30). Elipsis biasanya bertujuan supaya kalimat dalam wacana lebih efektif. Konjungsi merupakan perangkai satuan bahasa dengan satuan bahasa dalam wacana (Sumarlam,2003:32). Konjungsi mempunyai makna 
bermacam-macam, antara lain konjungsi yang menyatakan sebab akibat, pertentangan, pemilihan, harapan, waktu, syarat, dan cara.

\section{Metode Penelitian}

Penelitian kohesi dalam NSK termasuk dalam penelitian deskriptif. Data dikumpulkan dengan cara menyimak pemakaian penanda kohesi leksikal yang terdapat dalam NSK. Langkah selanjutnya mencatat penggalan wacana yang mengandung kohesi leksikal dan kohesi gramatikal yang terdapat dalam novel tersebut pada kartu data. Dalam kegiatan analisis data digunakan teori analisis wacana khususnya kohesi .

\section{Hasil dan Pembahasan}

Hasil penelitian menunjukkkan bahwa kohesi leksikal yang terdapat dalam NSK yaitu repetisi, sinonim, antonim, hiponim, kolokasi, dan equivalensi.

\section{Repetisi}

Berikut ini contoh repetisi yang ditemukan dalam NSK.

(1) Bila aku lapar, dia suka memasak untukku. Bila aku kesepian, dia akan menemaniku. Bila aku kesulitan mengerjakan tugas dari sekolah, ia akan mengajarkan aku ( Halaman 5-6)

Contoh (1) menggunakan repetisi anafora karena dalam contoh tersebut terjadi pengulangan satuan lingual bila aku di awal kalimat. Bila aku dalam penggalan wacana tersebut ulang sampai tiga kali. Hal tersebut untuk memperjelas atau menunjukkkan bahwa kakak Keke orang yang suka membantu Keke sekaligus sangat perhatian terhadap Keke. Jadi, peran kakak kedua Keke dapat diandalkan dalam segala hal diperjelas dalam kalimat berikutnya.

(2) Aku sadar mereka begitu mencintaiku. Aku sadar, aku tidak sendirian menghadapi duniaku. ( Halaman 89)

Contoh (2) menggunakan repetisi anafora. Dalam contoh tersebut aku sadar di awal kalimat pertama diulang di awal kalimat kedua. Kata sadar dalam contoh di atas berarti 'tahu dan mengerti'. Pengulangan aku sadar tersebut untuk menegaskan bahwa untuk menghadapi penyakit yang dialami, Keke tidak sendirian karena masih ada keluarga yang sangat mencintainya. Hal tersebut membuat perasaan Keke menjadi senang. 
(3) ...mengangkat kanker ini melalui operasi. Operasi yang harus dilakukan adalah memotong tulang pipi lalu mata dan yang terakhir mengangkat setengah dari wajah pasien (Halaman 42)

Contoh (3) mengunakan repetisi anadiplosis. Kata yang diulang dalam contoh (3) adalah kata operasi. Kata operasi dalam contoh (3) berarti 'bedah.'Pengulangan kata operasi tersebut untuk menjelaskan bagian-bagian yang harus diangkat. Hal tersebut terdapat dalam kalimat kedua.

(4) Aku terserang tumor. Tumor adalah penyakit pembengkakan pada bagian tubuh. (Halaman 57)

Contoh (4) juga mengunakan repetisi anadiplosis. Dalam KBBI (2000:1221) kata tumor berarti 'pembengkakan jaringan tubuh karena ketidaknormalan kondisi'. Pengulangan kata tumor dalam kalimat kedua berfungsi untuk menjelaskan pengertian tumor.

(5) Aku tidak melihat selelai rambutku yang terjatuh seperti biasanya di pundakku.

Ternyata, reaksi kemoterapi itu membuat sehelai rambutkku mulai berguguran. (Halaman 184)

Contoh (5) menggunakan repetisi mesodiplosis. Dalam contoh (5) terdapat pengulangan frasa yaitu selelai rambutku. Pengulangan frasa sehelai rambutku menegaskan bahwa efek kemoterapi menyebabkan rambut Keke rontok. Jadi, pengulangan dalam contoh (5) menunjukkan bahwa satuan lingual yang diulang tersebut dianggap penting.

\section{Sinonim}

Sinonim yang ditemukan dalam NSK adalah sinonim antarkata, sinonim antarfrasa, dan sinonim antarkalimat. Perhatikan wacana berikut ini.

(6) Ataupun kita harus mencari pengobatan seperti dulu, Keke rela asal bersama ayah. Keke rela ayah. Keke ikhlas. (Halaman 175)

Dalam contoh (6) terdapat kata yang bersinomin yaitu rela yang disebutkan dalam kalimat pertama, kedua, dan ketiga dan ikhlas yang disebutkan dalam kalimat keempat. Kata rela berarti 'bersedia dengan ikhlas hati', sedangkan ikhlas berarti'tulus hati'. Sinonim rela dan ikhlas dalam contoh (6) digunakan untuk menegaskan bahwa pengobatan apa pun yang akan dilakukan ayah Keke, dia ikhlas menerima asalkan dia bersama ayahnya. 
(7) Teman-teman mulai menyiapkan belajar kelompok di rumahku. Kami telah berjanji bukan hanya untuk kumpul-kumpul bergosip tapi kami akan belajar bersama. (Halaman 118)

Contoh (7) kepaduan wacana didukung oleh penggunaan sinomin antarfrasa yaitu frasa belajar kelompok pada kalimat pertama dan frasa belajar bersama dalam kalimat kedua. Belajar berkelompok lebih dapat membangkitkan semangat belajar jika dibandingkan dengan belajar sendirian. Akan tetapi, yang biasanya terjadi yaitu banyak bergosip. Hal tersebut tidak diinginkan oleh kelompok belajar Keke.

(8) Aku yang sedang disuap bubur oleh ayah terkejut ketika Prof. memasuki kamarku dengan wajah seperti itu. Ia duduk di antara kami dan kali ini dia bersikap jujur di hadapanku dan ayah. Tidak ada lagi rahasia di antra kami. Dia tidak ingin menutupi seтиa keadaanku. (Halaman 143)

Dalam contoh (8) kepaduan dibangun dengan menggunakan sinonim berupa kalimat. Kalimat kedua ...dia bersikap jujur dihadapanku dan ayah mempunyai makna yang sama dengan kalimat kedua tidak ada lagi rahasia di antara kami dan kalimat ketiga dia tidak ingin menutupi sетиa keadaanku kalimat keempat. Kalimat tersebut mempertegas isi kalimat pertama yang menyatakan bahwa Keke terkejut melihat dokter memasuki kamarnya dengan wajah yang berbeda karena dokter akan memberitahukan kondisi Keke sebenarnya. Jadi, sinomin dalam contoh (8) digunakan untuk mempertegas maksud.

\section{Antonim}

Istilah lain yang sering digunakan untuk menyebut antonim adalah oposisi. Oposisi dalam NSK yaitu oposisi relasional, oposisi mutlak, dan oposisi kutup. Perhatikan wacana berikut ini.

(9) Oh sahabatku, andai saja kau tahu sosok ibu dalam hidupku nyaris telah hilang ketika perceraian ibu dengan ayahku. Ibu telah menjalankan kehidupannya sendiri. (Halaman 103)

Kapaduan wacana dalam contoh (9) dibangun dengan menggunakan opisisi relasional. Hadirnya kata ibu menyebabkan hadirnya kata ayah. Dalam contoh (9) oposisi tersebut digunakan untuk menjelaskan bahwa ketika ibu dan ayahnya bercerai sosok ibu nyaris hilang. Hal tersebut dipertegas dengan kalimat berikutnya yaitu ibu telah menjalankan kehidupannya 
sendiri. Kata ibu dalam contoh (9) ditonjolkan dengan cara menempatkan posisi kata ibu di depan dalam frasa ibu dan ayahnya. Penonjolan kata ibu untuk menggabarkan bahwa Keke merasa sangat sedih karena tidak bersama ibu lagi.

(10) Ayah ... masih trauma dengan rumah tangganya yang gagal. ... aku yang mungkin pernah bangga dengan keluarga utuh yang dulu kumiliki. (Halaman 22)

Dalam contoh (10) terdapat oposisi mutlak rumah tangganya yang gagal dan keluarga utuh. Rumah tangganya yang gagal dan keluarga utuh merupakan oposisi mutlak karena makna keduanya bertentangan. Rumah tangga yang gagal dalam contoh (10) berarti 'rumah tangga yang ayah dan ibunya bercerai' sedangkan keluarga utuh berarti 'keluarga yang ayah ibunya bersatu'. Dalam contoh (10) rumah tangga yang gagal menyebabkan ayah dan Keke merasa kesepian. Keke membandingkan kondisi sekarang dengan kodisi dulu merasa bangga dengan keluarga yang utuh.

(11) Tapi akibat dari operasi itu adalah bekas lukanya yang sangat riskan karena bisa membuat cacat. Bodohnya aku tidak berpikiran ke sana. Akhirnya aku menyadari mengapa ayah menghindari operasi sebisa mungkin. (Halaman 65)

Dalam contoh (11) terdapat oposisi mutlak yaitu kata operasi dan menghindari operasi. Kedua kata tersebut bertentangan secara mutlak karena operasi berarti 'bedah'sedangkan tanpa operasi berarti 'tanpa bedah'. Kedua oposisi tersebut digunakan untuk menjelaskan akibat yang ditimbulkan oleh operasi bekas lukanya sangat riskan dan bisa membuat cacat sehingga ayah Keke memilih menghindari operasi.

(12) Andi telah bersamaku dalam suka dan duka sepanjang tahun ini menemani aku kekasihnya yang berpenyakit. Ia tidak harus lagi menderita karena aku. Ia harus bahagia tanpa aku saat ini. (hal 156)

Contoh (12) kepaduan wacana dibangun dengan menggunakan oposisi kutub menderita dan bahagia. Kata menderita dan bahagia merupakan oposisi kutub karena kedua kata tersebut tidak bertentangan secara mutlak. Kata tersebut mempunyai gradasi. Kata menderita mempunyai gradasi menderita, lebih menderita, sangat menderita dan paling menderita. Kata bahagia mempunyai gradasi kurang bahagia, agak bahagia, cukup bahagia, bahagia, lebih bahagia, dan sangat bahagia. 


\section{Kolokasi}

Kolokasi yang ditemukan dalam NSK adalah sebagai berikut.

(13) ... aku duduk di bangku kelas 6 SD. .. guru-guru sangat ramah ... apakah aku bisa mengikuti pelajaran sedangkan dalam hitungan bulan aku harus mengikuti ujian akhir sekolah. (Halaman 8)

Kepaduan wacana contoh (13) dibangun dengan menggunakan kata-kata lingkungan sekolah yaitu kelas 6 SD, guru-guru, pelajaran dan ujian akhir sekolah.Kata-kata tersebut digunakan untuk menceritakan kegelisahan Keke ketika pindah di sekolah yang baru.

(14) Ternyata aku tidak bodoh-bodoh banget untuk tinggal kelas. Saat pembagian rapor aku memang tidak juara kelas tapi tetap naik kelas dan tidak juga masuk peringkat terakhir di kelasku. Ayah senang melihat hasil ujianku. (Halaman 98)

Contoh (14) mencertakan prestasi Keke waktu sakit. Dalam penggalan wacana di atas Keke menjelaskan saat pembagian rapor Keke tidak jadi juara kelas, namun ia juga tidak masuk peringkat terakhir. Memang Keke tidak menjadi juara kelas. Hal tersebut diceritakan karena sebelum sakit Keke merupakan anak yang berprestasi. Jadi, meskipun kondisinya sakit dia tetap naik kelas. Jadi untuk, menceritakan kondisi Keke pada saat membagian rapor digunakan kata-kata rapor, juara kelas, naik kelas, peringkat, dan hasil ujian.

(15) Dokter membuat keputusan bahwa aku harus dirawat inap hari ini juga di rumah sakit... beberapa pemeriksaan dilakukan dalam tubuhku. ... suster menyiapkan sebuah alat ....(Halaman 197)

Dalam contoh (15) kepaduan wacana dibangun dengan kolokasi berupa satuan lingual yang berhubungan dengan rumah sakit yaitu dokter, memeriksa, pemerksaan, dirawat inap, dan suster. Satuan lingual tersebut digunakan untuk menggarkan keadaan Keke ketika di rumah sakit.

\section{Hiponimi}

(16) ... seluruh keluargaku ada di sampingku. Ayah, ibu, kedua kakakku, paman dan bibi serta teman-temanku telah ada di sampingku. (Halaman 210)

(17) Kanker dalam tubuhku menyebar ke seluruh organ tubuhku mulai kepalaku ..., hidungku ..., serta paru-paruku (Halaman 203) 
Kepaduan wacana dalam contoh (16) dibangun oleh adanya hipomim. Kata keluarga merupakan superordinat. Kata keluarga dijelaskan subordinatnya yaitu Ayah, ibu, kedua kakakku, paman dan bibi. Hiponim dalam contoh (16) digunakan untuk menjelaskan kondisi Keke setelah siuman dari koma. Ia melihat keluarga di sampingnya. Dalam contoh (17) seluruh organ tubuh merupakan superordinat dan subordinatnya adalah kepala, hidung, dan paru-paru.Contoh (17) menjelaskan kondisi kanker Keke yang menyebar keseluruh organ tuhnya dari kepala, hidung, dan paru-paru.

\section{Ekuivalensi}

Ekuivalensi yang ditemukandalam NSK adalah sebagai berikut.

(18) ... aku pun belajar dengan giat dan melupakan ... menggantinya dengan bukubuku pelajaran sekolah. Aku juga meminta Kiki untuk mengajarkan hal yang aku tidak pahami. (Halaman 8)

Kepaduan wacana dalam contoh (18) dibagun dengan menggunakan ekuivalensi. Dalam penggalan wacana di atas diceritakan perjuangan Keke belajar tanpa menyerah meskipun kondiri fisiknya sudah lemah. Sebelumnya untuk mengisi waktu Keke sering membaca komik. Dalam contoh (18) terdapat kata belajar, pelajaran, dan mengajarkan yang memilliki hubungan kesepadanan. Kata belajar, pelajaran, dan mengajarkan dibentuk dari kata ajar. Ajar dalam contoh tersebut mengalami proses penambahan afiks $\{m e-\},\{p e-a n\}$, dan $\{m e-$ kan\} sehingga terbentuk kata belajar, pelajaran, dan mengajarkan. Belajar dan mengajarkan berkategori verba dan pelajaran berkategori nomina.

(19) Sebelumnya aku harus benar-benar memastikan kanker itu lenyap. ... Kepastian akan penyakit itu lenyap, dapat dipastikan. (Halaman 91)

Kepaduan wacana dalam contoh (19) dibangun dengan ekuivalensi. Dalam contoh (19) terdapat kata memastikan, kepastian, dan dipastikan. Kata memastikan, kepastian, dan dipastikan tersebut berasal berasal dari kata pasti yang mengalami proses afiksasi. Adapun afiks yang membentuknya yaitu afiks \{me-kan\}, \{ke-an\}, dan \{di-kan\}. Kata memastikan berkategori verba aktif, dipastikan berkategori verba pasif, dan kepastian berkategori nomina.

\section{Kohesi Gramatikal}

Kohesi gramatikal yang digunakan dalam NSK adalah pengacuan, penyulihan, pelesapan, dan perangkaian. 


\section{Pengacuan}

Pengacuan yang digunakan dalam NSK yaitu pengacuan persona, pengacuan demonstrativa, dan pengacuan komparatif. Perhatikan wacana berikut ini.

(20) Aku bisa bernafas sedikit panjang karena guru Inggris kami sudah datang. Beliau juga sedikit terkejut dengan apa yang aku pakai. (Halaman 31)

(21) Untuk pria lain di luar keluargaku yang aku sayang, hanya dia yang aku cintai. Namanya Andi (Halaman 16)

(22) Setelah itu aku mengucapkan terima kasih kepada Kak Putri yang sudah meluangkan waktunya untukku. Saat itu aku sadar kalau aku mulai tumbuh menjadi gadis yang lebih dewasa. (Halaman 20)

(23) Aku pun berhenti di toilet wanita yang tak jauh dari kantin. Di sana aku menangis dan aku mengurung diri. (Halaman 56)

(24) Mereka lebih memilih berbicara dengan ayahku, bukan kepadaku. Berbeda dengan yang lainnya, Prof Muklis lebih ingin berbicara secara pribadi padaku.(Halaman 78)

Dalam contoh (20) kata beliau merupakan pronomina persona ketiga tunggal yang mengacu pada guru bahasa Inggris. Pengacuan dalam contoh (20) tersebut bersifat anaforis. Contoh (20) berbeda dengan contoh (21). Kata dia dalam contoh (21) dalam kalimat pertama mengacu pada Andi dalam kalimat kedua. Pengacuan dalam contoh (21) bersifat kataforis. Dalam contoh (22) digunakan pengacuan demonstrativa waktu saat itu. Saat itu mengacu pada kalimat sebelumnya yaitu setelah aku mengucapkan terima kasih kepada Kak Putri yang sudah meluangkan waktunya untukku. Saat itu menunjukkan adanya dua kegiatan yang bersamaan yaitu setelah Keke mengucapkan terima kasih kepada Kak Putri dan Keke sadar kalau dia mulai tumbuh mejadi gadis yang lebih dewasa. Dalam Contoh (23) digunakan pengacuan tempat di sana. Kata di sana mengacu pada di toilet wanita yang tak jauh dari kantin. Dalam contoh (24) digunakan pengacuan komparatif berbeda dengan yang lainnya. Pengacuan komparatif ini membandingkan antara kebiasaan dokter-dokter yang telah memeriksa Keke sebelumnya dan Prof, Mukhlis. Ketika Keke dan ayahnya berkunjung ke dokter-dokter sebelumnya, dokter lebih memilih berbicara dengan ayah Keke. Namun, Prof Muklis berbeda. Dia ingin berbicara dengan Keke. 


\section{Substitusi}

Substitusi juga ditemukan dalam NSK. Perhatikan wacana berikut ini.

(25) Oh iya, tak lupa kukenalkan pahlawan keluarga kami. Dia adalah raja di istana kami. Ayahku teman sekaligus pacar abadiku. (Halaman 6)

(26) Aku dan kedua kakakku seperti kehilangan semangat untuk hidup. Kami mulai malas untuk sekolah dan melakukan kegiatan di luar itu. (Halaman 7)

(27) Kami berempat: ayah, Kak Chika, Kak Kiki, dan aku menang selalu menggunakan kesempatan makan malam sebagai tempat berkumpul agar kebersamaan tetap tercipta. Itu sudah kami lakukan sejak ayah belum bercerai dengan ibu. (Halaman 28)

Dalam contoh (25) frasa pahlawan keluarga kami disubstitusi dengan frasa raja di istana kami. Dalam kalimat berukutnya terdapat frasa ayahku dan pacar abadiku. Penggantian sebutan ayah dengan pahlawan keluarga kami, dan pacar abadiku mengisyaratkan bahwa hubungan ayah dan anak sangat dekat dan ayah Keke sangat memperhatikan anak-anaknya. Jadi, dalam contoh (25) terdapat substitusi frasa dengan frasa. Dalam contoh (26) frasa $a k u$ dan kedua kakakku disubstitusi dengan kata kami. Dalam contoh (27) kami berempat: ayah, Kak Chika, Kak Kiki, dan aku menang selalu menggunakan kesempatan makan malam sebagai tempat berkumpul agar kebersamaan tetap tercipta disubstisusi dengan kata itu Dalam contoh (27) kalimat disubstitusi dengan kata. Subtitusi dalam contoh (24-27) tersebut menjadiikan kalimat lebih padu.

\section{Elipsis}

(28) Keke... Di sini nggak ada yang mau Keke gundul. Ayah dan Pak Mukhlis juga nggak mau... tapi ini Tuhan yang mau...Keke jangan takut gundul. Setelah sembuh, rambut Keke akan tumbuh lagi. (Halaman 134)

Dalam contoh (28) elipsis ditandai oleh tanda titik tiga yang terletak setelah kata mau. Satuan lingual yang dilesapkan yaitu Keke gundul. Contoh (9) lengkapnya menjadi

(28a) Keke.... Di sini nggak ada yang mau Keke gundul. Ayah dan Pak Mukhlis juga nggak mau Keke gundul tapi ini Tuhan yang mau Keke gundul. Keke jangan takut gundul. Setelah sembuh, rambut Keke akan tumbuh lagi. 
Elipsis dalam contoh (28) sengaja dibuat penulis agar pembaca dapat menafsirkan kata yang dihilangkan. Elipsis tersebut menyebabkan kalimat lebih estetis karena kata yang dihilangkan merupakan efek kemoterapi yaitu gundul.

\section{Konjungsi}

Penggunaan konjungsi dalam NSK dapat dilihat dalam contoh berikut ini.

(29) Bibi langsung mengambilkan obat tetes mata. Setelah itu aku langsung menuju mobil untuk berangkat ke sekolah. (Halaman 30)

(30) Aku bersyukur saat aku sulit seperti ini tidak ada sedikit pun sahabatku lari dariku. Bahkan Angel yang tidak menyukaiku datang untuk memberikan aku semangat. (Halaman 85)

(31) Ayah curiga melihatku ketika aku sedang makan. Ia selalu melirik kearahku, tetapi aku berpura-pura tidak tahu. Padahal untuk mengangkat sendok saja rasanya aku sudah kehabisan tenaga tapi aku memaksa untuk makan sebanyak mungkin walau aku kehilangan mood untuk makan, (Halaman 119)

(32) Reaksi obat ini sangat keras, bahkan membakar jaringan lunak kulit yang membuat diriku seolah seperti bayi yang baru lahir dan tanpa sehelai rambut di mana pun. Selain itu aku juga merasakan rasa panas dan mual yang luar biasa.

Kepadauan wacana contoh (29) ditandai oleh pemakaian konjungsi setelah itu. Konjungsi setelah itu merupakan konjungsi yang menyatakan 'perurutan', yaitu pertalian semantik yang menyatakan perbuatan atau peristiwa secara berturut-turut. Jadi, peristiwa dalam kalimat kedua aku langsung menuju mobil untuk berangkat ke sekolah terjadi setelah peristiwa dalam kalimat pertama bibi langsung mengambilkan obat tetes mata. Konjungsi bahkan dalam contoh (30) merupakan konjungsi yang menandai pertalian makna 'lebih'. Maksudnya apa yang dinyatakan pada klausa yang mengikuti konjungsi melebihi apa yang dinyatakan pada klausa lainnya. Dalam contoh (30) kalimat Angel yang tidak menyukaiku datang untuk memberikan aku semangat lebih baik dari pada kondisi yang dialami Keke dalam kalimat pertama aku bersyukur saat aku sulit seperti ini tidak ada sedikit pun sahabatku lari dariku. Jadi, dalam kondisi sakit teman Keke tidak ada yang menjauh. Di samping itu Angel yang biasanya tidak menyukainya pun datang. Konjungsi padahal dalam contoh (31) untuk menunjukkan pertentangan antara kondisi Keke yang sesungguhnya yaitu sebetulnya dia 
sudah lemah atau sudah kehabisan tenaga meskipun hanya mengangkat sendok dengan makan sebanyak mungkin meskipun dia sebetulnya tidak selera makan. Kepaduan wacana dalam contoh (32) dibangun dengan menggunakan konjungsi selain itu. Konjungsi selain itu dalam contoh (32) menyatakan tambahan penjelasan terhadap kalimat di mukanya. Kalimat pertama reaksi obat ini sangat keras, bahkan membakar jaringan lunak kulit yang membuat diriku seolah seperti bayi yang baru lahir dan tanpa sehelai rambut di mana pun kemudian diberi penjelasan tambahan pada kalimat kedua aku juga merasakan rasa panas dan mual yang luar biasa.

\section{Simpulan}

Setelah dianalisis ditemukan bahwa untuk membentuk wacana yang padu penulis novel Surat Kecil untuk Tuhan menggunakan penanda kohesi leksikal dan gramatikal. Penggunaan penanda tersebut agar terbentuk wacana lebih padu sehingga wacana mudah dipahami pembaca. Di samping itu, penggunaan penanda kohesi leksikal juga digunakan untuk menegaskan dan memperjelas maksud kalimat.

\section{Daftar Pustaka}

Djajasudarma, T. Fatimah. 1994. Wacana pemahaman dan Hubungan Antarunsur. Bandung: PT Eresco.

Pateda, Mansoer. 1996. Semantik Leksikal. Jakarta:Rineka Cipta.

Pusat Bahasa dan Departemen Pendidikan Nasional. 2005. Kamus Besar Bahasa Indonesia.Jakarta: Balai Pustaka.

Sumarlam. 2003. Analisis Wacana Teori dan Praktik. Surakarta: Pustaka Cakra.

Rani, Abdul, Bustanul Arifin, dan Martutik. 2004. Analisis Wacana: Sebuah Kajian Bahasa dalam Pemakaian. Cetakan Pertama. Jakarta: Bayumedia Publishing.

Wijana. I Dewa Putu dan Muhammad Rohmadi. 2011. Semantik Teori dan Praktik. Surakarta: Yuma Pustaka.

Sumber Data

Daavonar, Agnes. 2008. Surat kecil untuk Tuhan. Jakarta: Inandra Publisher. 